\title{
TUNING INTO THE TASK: SONIC ENVIRONMENTAL CUES AND MENTAL TASK SWITCHING
}

\author{
Toby Gifford \\ Griffith University \\ Queensland Conservatorium of Music \\ 140 Grey St. Southbank QLD 4169 \\ t.gifford@griffith.edu.au
}

\begin{abstract}
This position paper suggests a novel approach to enhancing productivity for professionals whose core business is deep thinking, by manipulation of the sonic environment. Approaching the issue from the perspective of sound-design, it proposes the composition and algorithmic generation of background soundscapes that promote a psychological state of flow [1], and can become mentally associated with particular tasks through exposure, so as to facilitate task switching by switching soundscapes.

These background soundscapes are intended to mask distracting clatter, oppressive quiet, and other suboptimal sonic environments frequently encountered in office workplaces. Consequently, I call them active-silencessoundscapes designed to be not heard, although they may be relatively loud. The most commonly used active-silence is white noise, though there are surprisingly diverse other approaches to crafting active-silence. This variety suggests the possibility of training associations that pair distinct active-silences with distinct mental tasks.
\end{abstract}

\section{INTRODUCTION}

Cordoning off blocks of uninterrupted time is a serious challenge for many professionals. In today's 'on-line' society multitasking is the norm and extended periods of time to concentrate on a single task are scarce. Yet deep thinking is core business for many professions. Moreover, some professions require several distinct types of deep thinking, and switching between them can be difficult. For example, one of the most challenging aspects of academic life is juggling the responsibilities of teaching and research. I usually need at least an hour to shift mental gears between these categories, particularly switching into the deep thinking required for research, writing, computer programming, or creative development.

Psychologists refer to this as task switching [2]. Many authors have highlighted the need for ways to minimise switching time - the time lost in switching to a new task in order to improve productivity and decrease stress in the workplace [3]. Environmental cues can aid resumption of suspended mental tasks, particularly by conditioning through association [4] and productivity tools that deliberately manipulate the visual environment to facilitate task switching are emerging [5]. However, the sonic environment does not appear to have been considered for this purpose. I suggest

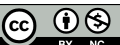

This work is licensed under Creative Commons Attribution - Non Commercial 4.0 International License.

The full terms of the License are available at

http://creativecommons.org/licenses/by-nc/4.0/ manipulation of the sonic environment may facilitate switching between different deep thinking tasks.

\section{HYPOTHESIS}

The hypothesis of this paper is that sonic conditioning through the use of background soundscapes may facilitate 'getting into the zone' when switching between different categories of deep thinking. I propose a compositional approach, using various forms of active-silence to create distinct sonic environments to associate with distinct mental activities.

The use of sound to condition automatic physiological responses has a long history, going at least back to Pavlov [6] and his dogs - by training dogs to associate sonic cues with subsequent feeding, Pavlov observed the dogs become conditioned to salivate in response to these sonic cues. It seems plausible that an analogous mental conditioning may be achieved through crafting background soundscapes that become associated with a particular mental activity.

There does not appear to have been any research conducted on whether association through exposure to background sound can assist in re-entering a particular mental state.

\section{ACTIVE SILENCE}

Whilst most psychological studies on environmental noise concentrate on its distracting effect [7],[8],[9], there are a number of studies that find cognitive benefits to certain types of background noise. For example studies have found that background white noise gives cognitive benefits to monkeys [10], geriatrics [11] and ADHD children [12], and promotes sleep in infants [13]. Di et. al [14] find that pink noise and certain FM tones can alleviate annoyance caused by low frequency environmental sound.

A rarely discussed issue with studies on the enhancing or distracting effect of background sound is the ambiguity of the control group. Typically such studies will compare the effect of various types of background sound to 'silence'. However, silence is a problematic notion. Loudness is relative; in the right context a pin drop can be piercing. In the absence of incident vibrational energy the ear will provide its own, and in an anechoic chamber purpose-built to be devoid of sound, the noise of one's heart beating and blood circulating becomes loud [15]. Occupational health \& safety regulations typically mandate maximum occupancy times of around an hour in these deafeningly silent chambers. Rather than an absence of sound, silence is better described as a culturally and contextually determined soundscape of familiarity.

I propose the term active-silence for a soundscape artificially generated (through technology) in order to create 
a silent quality. Active-silence is designed to be not heardto only be perceptible when it ceases. Various types of active-silence are becoming increasingly popular. White noise generators for the bedroom can now be found on Amazon and eBay, and there is a proliferation of noisestreaming websites, offering a selection of noise colours (white, brown, pink) along with various other 'calming' soundscapes, typically recordings of rain, the ocean, or other natural environments. For example, whilst writing this paper I have been listening to various soundscapes from soundrown (http://soundrown.com). Curiously, I have found that for me the 'cafe' setting seems most conducive to writing. Try it yourself and see what works best for you! It's interesting since the cafe setting is quite noisy. The sound of the barista banging the group-head to empty the used coffee is ostensibly quite loud and intrusive.

\subsection{Sound-masking}

Since the 1970s there has been a commercial industry of active-silence generation for workplaces, often called soundmasking. The idea of sound-masking is to raise the noise floor with a relatively spectro-temporally homogeneous sound, such as white noise, so that other unwanted sounds are less noticeable. White noise per se is not typical for commerical office installations. For example, the following is taken from marketing material for a commercial soundmasking system manufacturer:

"Q: Isn't a sound masking system the same as white noise?

A: The term white noise describes a specific type of used in early masking systems in the 1970s. These systems were inflexible and the hissing quality of their sound prevented widespread acceptance ... The Logison Acoustic Network makes an engineered sound comparable to that of a soft airflow." [16]

Pink noise, by which is meant noise with a spectrum whose power is inversely related to frequency, is more commonly used in practice, whilst Logison (for example) markets its product as 'green noise', presumably alluding to its naturalesque qualities - though they do not give any details on the synthesis process. Pink noise, also called 1/f noise, has been written about at length as a sort of spookily ubiquitous phenomenon, akin to the fibonnaci series or the golden ratio, that pops up repeatedly in nature [17] and in music [18]. Treasure [19] similarly recommends naturalesque sounds for sound-masking, particularly "water, wind or waves".

\subsection{Natural Soundscapes}

A number of studies have found evidence of positive and restorative effects of natural soundscapes [20], [21], [22], [23], [24]. Moreover, natural soundscapes that induce feelings of tranquility and pleasantness exhibit dramatic heterogeneity in terms of quantitative acoustical descriptors [25], [20], [26], and even in terms of other subjective descriptors [27].

However, playing back recordings of natural soundscapes in an office environment is problematic. It seems to be important for soundscapes to not be overtly incongruous with the visual surrounds [23], [26], [28]. Many natural soundscapes contain particular sounds that are readily recognisable, such as bird-calls, that seem odd in an interior setting.
Yet the abstract sonic qualities of natural soundscapes suggest a point of departure for the creation of active-silences, by mimicing these qualities without the particular and recognisable sounds of a wilderness field recordings: properties such as spatial engulfment [29], acoustic richness [30], acoustic complexity [25] and acoustic diversity [31].

For the purposes of this paper, the great diversity of natural soundscapes that promote tranquility adds confidence to the notion that a variety of active-silences may be created, different enough to condition distinct tasks with distinct soundscapes, whilst remaining undistracting.

\subsection{Background Music}

The notion that intentional background sound can enhance workplace productivity is not new: the Muzak corporation claimed exactly this from inception in the 1930s all the way through to bankruptcy in 2009, though the scientific rigour of their self-funded studies is disputed [32]. What is not disputed is Muzak's lack of artistic merit: "people began to use the company's name as a generic term for anything bland, soulless, and uninspired - so much that today many don't realize that the word has a non-perjorative application" [33].

The Muzak corporation's own research suggested that continuous Muzak was counterproductive (and unpalatable workplaces would simply switch it off after a while) and instead opted for alternating periods of 15 minutes of Muzak followed by 15 minutes of "silence" [33].

The intentions of this paper are quite different to the goals of Muzak. Muzak was conceived in a modernist frame at the height of the Scientific Managerialism of Frederik Taylor [34], where workers where considered as " $\operatorname{cog}[\mathrm{s}]$ in the machinery" [36] inspired by the production lines of Ford Motors. Like much of the modernist program of controlover-nature a side-effect was greater homogenisation of our lived experience. Modernist architecture similarly sought to erode acoustic idiosyncrasy: "reverberation equations, sound meters, microphones, and acoustical tiles were deployed in ... office skyscrapers. The control provided by these technologies, however, was applied in ways that denied the particularity of place, and the diverse spaces of modern America began to sound alike as a universal new sound predominated." [37].

Critical responses to this modernist acoustic homogenisation included John Cage's never realised MuzakPlus [33], and Brian Eno's Ambient Music: "whereas the extant canned music companies proceed from the basis of regularizing environments and blanketing their acoustic and atmospheric ideosyncracies, Ambient Music is intended to enhance these" [37]. Yet, despite the proliferation of ambient music as a genre tag, "Eno's mini-manifesto about ambient music became less interesting to him with time, and [ambient music] became something of a moving target, meant to accomplish very different goals, some of which surely had much to do with marketing." [38].

Other approaches to understanding everyday environmental sound emerged in the 70 s with Murray Shafer, Barry Truax and others intitiating the World Soundscape Project and the field of Acoustic Ecology [39]. Schafer argued that the invention of the window marked a significant turning point in human phenomenal experience where the soundscape and the visual scene became decoupled. In parallel, a number of theorists across sound studies, urban planning, and cultural theory discussed the contradictions 
between treatment of sound in planning \& law compared with sonic experience[40].

Yet despite these diverse strands of criticism and resistance to modernist soundscape approaches, practical application of these ideas indoors remain mostly confined to concerts or installations. The post-modern vision of interior acoustic environmental design is yet to be realised.

More recently, since Rauscher et al. [41] promoted the Mozart Effect-claiming that playing Mozart in the background during study enhances learning outcomes - there has been a hive of research activity investigating the influence of background music \& sound on concentration, productivity, and learning. This area has been the subject of quite some controversy, of which more below, but it does focus on techniques for enhancing concentration over our timescales of interest, i.e. periods of several hours. None of these studies on background music \& sound appear to explicitly consider the effect on task switching, though one might hypothesise that a concentration-enhancing technique is likely to decrease switching time. On the other hand it may be that deeper concentration comes at the cost of cognitive flexibly.

Controversy over the Mozart Effect has centred on the authors' claims that something about the genius of Mozart enhances cognitive ability whilst listening. Thompson et al. [42] argue that there is nothing inherently superior about Mozart's music in producing this effect; rather it is simply the case that people learn better when listening to music that they liked and are familiar with - the original researchers just happened to choose subjects who knew and liked Mozart.

\section{GETTING INTO THE ZONE}

A key consideration for productivity in an office environment is the time it takes to 'get in the zone', particularly given the frequency with which interruptions can be typically expected in many workplaces. Whilst there is a wealth of psychological literature relating to attention, concentration and distraction in multi-tasking environments, much of this research considers either very short timescales, or is primarily concerned with fatigue. For assessing the kinds of mental states of interest here, which may take around an hour to achieve, and last for several hours, I suggest flow theory.

\subsection{Flow}

The notion of the psychological state of flow was developed by Czikszentmihalyi $(1990 / 1975)$ in his studies of peak experience. A flow state is one of effortless concentration, accompanied by high intrinsic motivation and positive emotion, sometimes described as "the zone" (Lafont 2015). The theory's key finding is that a balance between challenge and skill is conducive to entering flow. Though originally developed to describe the sorts of peak experiences often reported by athletes, musicians, and other high achieving individuals, "it is important to note that flow is ... not usually regarded as an all-or-nothing peak experience; rather, degree of flow is a continuous variable that can be used to characterize the experiential quality of any everyday activity" (Csikszentmihalyi \& Csikszentmihalyi, 1992), and has been applied to workplace experience in particular (Eisenberger et al. 2005)

\subsection{Mental Context Switching}

A number of studies, mostly in cognitive psychology, have examined switching time mitigation techniques in various contexts, for example driving whilst talking on the phone. The tasks typically studied are moment-to-moment, rather than requiring cohesive cognition over larger timescales, and the switching times are very short. Wickens et al. comment:

"Numerous models of sequential operations in multitask performance can be found, and these can be positioned along a time-scale continuum ... the majority of such models appear to lie toward the 'micro' end of the continuum, modeling task switching times in the order of milliseconds ... Often, their focus is exclusively on time, and on accounting for variance in multi-task performance time required to carry out relatively simple cognitive activities" [43]

Studies that investigate longer timescales - on the order of hours, and complex cognitive tasks such as involved in research and writing, are few.

Environmental cues can stimulate recall of mental states formed in the environment from which the cues are taken. Smith \& Vela suggest "the reinstatement of context cues ... should benefit memory for information learned in the reinstated environment" [44] although the kinds of experimental manipulations they surveyed typically involved moving subjects between physically different environments (i.e. different rooms). The challenge this position paper explores is how to artificially modify an environment that is physically fairly static - sitting in the same room on the same chair looking at the same computer screen - to allow these artificially created cues to assist in switching mental states.

\section{PROPOSED APPROACH}

This position argued in this paper is that creating background soundscapes for everyday environments should be approached as applied composition/sound-design — an exploration, parameterisation, and evaluation of activesilences. The aim of these active-silence compositions would be to assist in 'getting into the zone' in two respects. First, the soundscapes should encourage flow. Second, the soundscapes should have some unique character to enable them to condition switching into a particular mental activity.

I expect the type of soundscapes that encourage flow will vary across people, locations and tasks. To provide depth and breadth, and enhance generalisability whilst retaining ecological validity, a multi-method investigation would be beneficial, including:

- Reflective practice by artist-researchers: longitudinal and iterative practice of composing active-silence, and evaluation of the success of sonic conditioning on the researcher's professional work - particularly the challenge of switching between research, writing, and creative development.

- User testing: development of software that can generate a variety of types of active-silence, allowing the user to select the appropriate silence for the task at hand - and evaluation of the success of the sonic conditioning for 'getting into the zone'.

One approach to evaluating the success of sonic conditioning could be comparison of the efficacy of different soundscapes in promoting flow. 


\subsection{Measuring Flow}

There are several reasons for using flow theory in this context, rather than other measures such as concentration or annoyance that are frequently used in studies of noise abatement (e.g. [9], [5]):

(i) Flow theory studies psychology in context. Nakumara \& Czikszentmihalyi emphasise that "a key characteristic [of] the flow model ... is interactionism ... Rather than focusing on the person, abstracted from context, flow research has emphasised the dynamic system composed of the person and the environment" [45]. Given the primary goal of this proposal is to help the mind perceive a new context despite substantial environmental similarity, through specific environmental modification, this seems apposite.

(ii) Flow theory has mostly been developed to account for cognitive experiences on the timescales of interest here - on the order of hours - whereas measures such as concentration and annoyance are shorter timescale, at least in the ways they have typically been operationalised in these studies.

I propose a novel evaluation tool for measuring flow, tentatively termed 'Enhanced Experience Sampling Method (EESM)'. The EESM would combine several existing research instruments and technologies, leveraging the recent development of portable ubiquitous computing and biomonitoring devices. In particular it would combine the traditional Experience Sampling Method for measuring flow with physiological markers and affective computing techniques. These components and their possible synthesis in the EESM are elaborated in the next few sections.

\subsection{Experience Sampling Method}

A standard approach to measuring flow is the experience sampling method [46] which is a regimented form of selfreporting on subjective qualitative experience. Typically the sampling is prompted by a some form of signalling device (originally Csikszentmihalyi used electronic paging devices). These authors argue that experience sampling offers the "unique advantage of ... its ability to capture daily life as it is directly perceived from one moment to the next, affording an opportunity to examine fluctuations in the stream of consciousness and the links between the external context and the contents of the mind" [46].

\subsection{Physiological Markers}

Experience sampling has some methodological disadvantages: it relies on the subjective opinions of the participants, and can be obtrusive-frequent interruptions may hinder flow. To address this various authors have sought to probe flow through observable physiological measures. De Manzano et al. found "a significant relation ... between flow and heart period, blood pressure, heart rate variability, activity of the zygomaticus major muscle, and respiratory depth" [47] and Keller et al. [48] find a challenge-skillbalance measure to be a common cause for both self-reported flow measurements and the psychophysiological markers heart-rate variability and salivary cortisol.

\subsection{Affective Computing}

Affective Computing is another body of research that seeks to link observable physical measures with underlying mental states. Having arisen from the field of Human-Computer
Interaction, it concentrates on the computational detection of human emotional states whilst interacting with a computer (originally in the context of artificial intelligence, but now more broadly applied). The primary methods used are rooted in computer vision, for example automated facial expression recognition [49]. As the kinds of tasks this paper is discussing are primarily computer-based, affective computing techniques (using for example the computer's webcam) could provide another stream of data for interrogating flow.

\subsection{Enhanced Experience Sampling Method (EESM)}

To evaluate flow in the workplace, an enhanced experience sampling method combining signal-prompted subjective qualitative self-reporting with objective quantitative psychophysiological measures including heart-rate variability and galvanic skin response, and affective computing measures, could be devloped. An important design element for implementing an experience sampling instrument is the sampling-schedule, which may be regular, random, or eventbased according to the needs of the project [46]. The availability of portable computing devices now means that it is feasible to construct an adaptive sampling-schedule, based on real-time feedback from physiological measures. In the early stages of exploring the efficacy of various background soundscapes in promoting flow, adaptive scheduling could be used to increase the power of tests relating flow states to physiological measures. Later, as these relationships become better established, adaptive scheduling could be used to strategically avoid interrupting moments of flow.

\section{CONCLUSION}

There is much to suggest that sonic conditioning of mental contexts is possible. It is established that both music and sound can condition emotion [50], enhance concentration [10], [12], [51], and stimulate recall of memories [52]. What has been less well understood is the broad variety of background sounds that can be used without causing distraction. It seems a reasonable extrapolation that training the mind to associate particular soundscapes with particular tasks may help switching between tasks by switching to the associated soundscape.

Other environmental variables are thought to assist in conditioning mental contexts. For example, amongst a growing population of telecommuters and work-from-home employees, freelancers or consultants, common strategies to address "work/home boundary permeability" [53] include deliberate environmental modifications such as setting up a physically separated 'home-office' and changing into workclothes. Furthermore, the ability to control one's sonic environment is often cited as a benefit of working from home [54]. It may be that the relatively sparse attention paid to workplace sound design reflects a general trend for sound to be of secondary concern in architecture [55].

On a task-based level, evidence from the HumanComputer Interaction field supports the notion of environmental conditioning (or priming) in facilitating mental contexts. For example, Altman \& Trafton's Memory for Goals theory [56] examines task resumption after an interruption in the workplace. Andrews et al. explain:

"over the course of an interruption, the activation level of the suspended primary task goal will decay and it will be more difficult to retrieve this goal upon 
resumption of the primary task. The activation level of the goal is dependent on two constraints: strengthening and priming $\ldots$ the priming constraint suggests that cues in the physical or mental environment influence activation by providing associative activation. Critically, an association between the cue and the suspended primary task goal must be established prior to the interruption." [57]

Kersten \& Murphy [58] provide empirical evidence that visual context priming can reduce task switching time, and boost productivity in the context of computer programming, and a growing number of software programs are available that attempt to organise computer monitor display according to task contexts, such as TaskTracer [59], User Monitoring Environment for Activities [59], and TaskTop [61]. None of these programs, however, consider the sonic environment.

The benefits of faster switching times, greater levels of workplace flow, and enhanced multitasking capacity, would be widespread. For most people who work in an office environment, multitasking has become the norm [62]. The pace of multitasking reduces productivity [63] and increases stress [64]. The issue is particularly problematic in academia [65].

This proposal is timely in that recent developments in personal physiological tracking and affective computing have made devices for these functions readily available to consumers, driven by a growing movement of personal biomonitoring, sometimes referred to as "The Quantified Self" [66]. These devices, such as the Samsung Simband and Fitbit surge smart-watches, and the Intel RealSense camera, provide an unprecedented level of detail whilst remaining fairly unobtrusive.

\section{REFERENCES}

[1] Csikszentmihalyi, M. (1990). Flow: The psychology of optimal experience. New York, NY: Harper \& Row.

[2] Soveri A et al. (2013). Set Shifting Training with Categorization Tasks. Edited by Bart Rypma. PLoS ONE 8 (12): e81693.

[3] Rubinstein, J. S., Meyer, D. E., \& Evans, J. E. (2001). Executive Control of Cognitive Processes in Task Switching. Journal of Experimental Psychology: Human Perception and Performance, 27(4), 763-797.

[4] Smith, S. M., \& Vela, E. (2001). Environmental contextdependent memory: A review and meta-analysis. Psychonomic Bulletin \& Review, 8(2), 203-220.

[5] Kersten, Mik, and Gail C. Murphy. 2015. "Reducing Friction for Knowledge Workers with Task Context.” AI Magazine 36 (2).

[6] Pavlov, I. P. (1902). The work of the digestive glands. London: Griffin.

[7] Edwards, B., Hafter, E., Kalluri, S., \& Sarampalis, A. (2009). Objective measures of listening effort: effects of background noise and noise reduction. Journal of Speech, Language and Hearing Research, 52(5), 1230+.

[8] Landström, U., Löfstedt, P., Akerlund, E., Kjellberg, A., \& Wide, P. (1990). Noise and annoyance in working environments. Environment International, 16(4), 555559.

[9] Errett, J., Bowden, E. E., Choiniere, M., \& Wang, L. M. (2006). Effects of noise on productivity: does performance decrease over time. Architectural Engineering Institute. 190(18).
[10] Carlson et al. (1997). "Effects of Music and White Noise on Working Memory Performance in Monkeys." NeuroReport 8: 2853-56.

[11] Burgio, L et al. (1996). Environmental "white noise": An intervention for verbally agitated nursing home residents: Journals of Gerontology: Series B: Psychological Sciences and Social Sciences Vol 51B(6) Nov 1996, P364-P373.

[12] Söderlund, Göran BW, Sverker Sikström, Jan M. Loftesnes, and Edmund J. Sonuga-Barke. 2010. "The Effects of Background White Noise on Memory Performance in Inattentive School Children.” Behavioral and Brain Functions 6 (1): 55.

[13] Forquer, LeAnne M., and C. Merle Johnson. 2005. "Continuous White Noise to Reduce Resistance Going to Sleep and Night Wakings in Toddlers." Child \& Family Behavior Therapy 27 (2).

[14] Di, G., Li, Z., Zhang, B., \& Shi, Y. (2011). Adjustment on subjective annoyance of low frequency noise by adding additional sound. Journal of Sound and Vibration, 330(23), 5707-5715.

[15] Cage, John. (1973 / 1937). Silence: Lectures and Writings by John Cage. Middletown, Connecticut: Wesleyann University Press.

[16] Logison (a). Understanding Sound Masking. Retrieved from http://www.logison.com/site Files/Content/PDF/ Logison_Understanding_Sound_Masking.pdf

[17] Handel PH \& Chung AL (1993) Noise in Physical Systems and 1/f Fluctuations. New York: American Institute of Physics.

[18] Voss, R. F., \& Clarke, J. (1978). "1/f noise" in music: Music from 1/f noise. Journal of the Acoustical Society of America 63: 258-263.

[19] Treasure, J. (2011). Sound business. Management Books 2000 Limited.

[20] De Coensel, B., \& Botteldooren, D. (2006). The quiet rural soundscape and how to characterize it. Acta Acustica United with Acustica, 92(6), 887-897.

[21] Lam, K.-C., Brown, A., Marafa, L., \& Chau, K.-C. (2010). Human Preference for Countryside Soundscapes. Acta Acustica United with Acustica, 96, 463-471.

[22] Yang, W., \& Kang, J. (2005). Acoustic comfort evaluation in urban open public spaces. Applied Acoustics, 66(2), 211-229.

[23] Brown, A. L. (2012). A review of progress in soundscapes and an approach to soundscape planning. Int. J. Acoust. Vib, 17(2), 73-81.

[24] Davies, W. J., Adams, M. D., Bruce, N. S., Cain, R., Carlyle, A., Cusack, P., ... Poxon, J. (2013). Perception of soundscapes: An interdisciplinary approach. Applied Acoustics, 74(2), 224-231.

[25] Farina, F., Bogaert, J., Schipani, J., 2005. Cognitive landscape and information: new perspectives to investigate the ecological complexity. BioSystems 79, 235-240.

[26] Pheasant, R., Horoshenkov, K., Watts, G., \& Barrett, B. (2008). The acoustic and visual factors influencing the construction of tranquil space in urban and rural environments tranquil spaces-quiet places? The Journal of the Acoustical Society of America, 123(3), 1446.

[27] Axelsson, Ö., Nilsson, M. E., \& Berglund, B. (2010). A principal components model of soundscape perception. The Journal of the Acoustical Society of America, 128(5), 2836. 
[28] Cerwén, G. (2016). Urban soundscapes: a quasiexperiment in landscape architecture. Landscape Research, 1-14.

[29] Paine, G., Sazdov, R., \& Stevens, K. (2007). Perceptual Investigation into Envelopement, Spatial Clarity, and Engulfment in Reproduced Multi-Channel Audio. In Audio Engineering Society Conference: 31st International Conference: New Directions in High Resolution Audio.

[30] Towsey, M., Wimmer, J., Williamson, I., \& Roe, P. (2014). The use of acoustic indices to determine avian species richness in audio-recordings of the environment. Ecological Informatics, 21, 110-119.

[31] Sueur, J., Gasc, A., Grandcolas, P., Pavoine, S., 2012. Global estimation of animal diversity using automatic acoustic sensors. In: Sensors for Ecology: Towards Integrated Knowledge of Ecosystems. CNRS Editions, pp. 101-119.

[32] Vanel, H. (2013). Triple Entendre: Furniture Music, Muzak, Muzak-Plus. University of Illinois Press.

[33] Owen, D. (2006, April 10). The Soundtrack of your Life: Muzak in the Realm of Retail Theatre. The New Yorker, 66-71, p. 69.

[34] Jones, S., \& Shumacher, T. (1992). Muzak: on functional music and power. Critical Studies in Mass Communication, 9(2), 156-169.

[35] Rosen, E. (1993). Improving Public Sector Productivity: Concepts and Practice. Thousand Oaks, CA: Sage Publications.

[36] Thompson, E. (2004). The Soundscape of Modernity: architectural acoustics and the culture of listening in America. Cambridge, MA: MIT Press.

[37] Eno, B. (1978/2004). Ambient music. Audio Culture. Readings in Modern Music, 94-97.

[38] Richardson (2002). As Ignorable as it is Interesting: the Ambient Music of Brian Eno. Pitchfork.

[39] Murray Schafer, Raymond. "The soundscape: Our sonic environment and the tuning of the world." Vancouver: Destiny Books (1977).

[40] LaBelle, B. (2010). Acoustic territories: sound culture and everyday life. A\&C Black.

[41] Rauscher, Frances H., Gordon L. Shaw, and Katherine N. Ky. "Listening to Mozart enhances spatial-temporal reasoning: towards a neurophysiological basis." Neuroscience letters 185, no. 1 (1995): 44-47.

[42] Thompson W et al. (2001). Arousal, Mood, and The Mozart Effect. Psychological Science 12 (3): 248-51.

[43] Wickens, Christopher D., Robert S. Gutzwiller, and Amy Santamaria. 2015. "Discrete Task Switching in Overload: A Meta-Analyses and a Model." International Journal of Human-Computer Studies 79 (July): 79-84.

[44] Smith, S. M., \& Vela, E. (2001). Environmental contextdependent memory: A review and meta-analysis. Psychonomic Bulletin \& Review, 8(2), 203-220.

[45] Nakamura, J., \& Csikszentmihalyi, M. (2002). The concept of flow. Handbook of positive psychology, 89105.

[46] Hektner, J. M., Schmidt, J. A., \& Csikszentmihalyi, M. (2007). Experience sampling method: Measuring the quality of everyday life. Sage.

[47] de Manzano, Ö., Theorell, T., Harmat, L., \& Ullén, F. (2010). The psychophysiology of flow during piano playing. Emotion, 10(3), 301-311.

[48] Keller, J., Bless, H., Blomann, F., \& Kleinböhl, D. (2011). Physiological aspects of flow experiences: Skills-demand-compatibility effects on heart rate variability and salivary cortisol. Journal of Experimental Social Psychology, 47(4), 849-852.

[49] Zeng, Z., Pantic, M., Roisman, G., \& Huang, T. S. (2009). A survey of affect recognition methods: Audio, visual, and spontaneous expressions. Pattern Analysis and Machine Intelligence, IEEE Transactions on, 31(1), 39-58.

[50] Eifert, G. H., Craill, L., Carey, E., \& O'Connor, C. (1988). Affect modification through evaluative conditioning with music. Behaviour Research and Therapy, 26(4), 321-330.

[51] Haake AB (2011). Individual Music Listening in Workplace Settings: An Exploratory Survey of Offices in the UK. Musicae Scientiae 15(1).

[52] Sacks, Oliver. 2007. Musicophilia: Tales of Music and the Brain. Picador.

[53] Gajendran, Ravi S., and David A. Harrison. 2007. "The Good, the Bad, and the Unknown about Telecommuting: s." Journal of Applied Psychology 92 (6): 1524-41.

[54] Pearlson, K. E., \& Saunders, C. S. (2001). There's no place like home: Managing telecommuting paradoxes. The Academy of Management Executive, 15(2), 117-128.

[55] Blesser, B \& Salter L. (2009). Spaces Speak, Are You Listening?: Experiencing Aural Architecture. MIT press.

[56] Altmann E \& Trafton JG (2002). Memory for goals: An activation-based model. Cognitive Science. 26(1), 39-83.

[57] Andrews A et al. (2009). "Recovering From Interruptions: Does Alert Type Matter?" Human Factors and Ergonomics 53 (4): 409-13.

[58] Kersten, M., \& Murphy, G. C. (2012). Task context for knowledge workers. In Proc. AAAI 2012 Activity Context Representation workshop.

[59] Dragunov, et al. 2005. "TaskTracer: A Desktop Environment to Support Multi-Tasking Knowledge Workers." In Proceedings of the 10th International Conference on Intelligent User Interfaces, 75-82. ACM.

[60] Kaptelinin, V. 2003. UMEA: Translating Interaction Histories into Project Contexts. In Proceedings of the 2003 ACM SIGCHI Conference on Human Factors in Computing Systems, 353-360. New York: Association for Computing Machinery.

[61] Kersten, M., \& Murphy, G. C. (2015). Reducing Friction for Knowledge Workers with Task Context. AI Magazine, 36(2).

[62] González, Victor M., and Gloria Mark. 2004. "Constant, Constant, Multi-Tasking Craziness: Managing Multiple Working Spheres." In Proceedings of the SIGCHI Conference on Human Factors in Computing Systems, 113-20. ACM.

[63] Leshed, Gilly, and Phoebe Sengers. 2011. "I Lie to Myself That I Have Freedom in My Own Schedule: Productivity Tools and Experiences of Busyness." In Proceedings of the SIGCHI Conference on Human Factors in Computing Systems, 905-14. ACM.

[64] Mark, Gloria, Daniela Gudith, and Ulrich Klocke. 2008. "The Cost of Interrupted Work: More Speed and Stress." In Proceedings of the SIGCHI Conference on Human Factors in Computing Systems, 107-10. ACM.

[65] Levy, David M. 2007. "No Time to Think: Reflections on Information Technology and Contemplative Scholarship." Ethics and Information Technology 9 (4): 237-49.

[66] Technology Quarterly. (2012). "The Quantified Self: Counting Every Moment.” The Economist. 